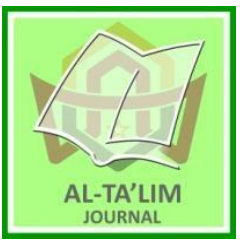

AL-TA'LIM JOURNAL, 28 (3), 2021, (190-203)

(Print ISSN 1410-7546 Online ISSN 2355-7893)

Available online at http://journal.tarbiyahiainib.ac.id/index.php/attalim

\title{
Instrumentalization vs Instrumentation of Microlearning in a Math Class
}

Received: $18^{\text {th }}$ March 2021 Revised: 02 ${ }^{\text {nd }}$ April 2021; Accepted: $30^{\text {nd }}$ November 2021

Permalink/DOI: http://dx.doi.org/10.15548/it.v28i3.690

Enrique Mateus-Nieves *)

Externado University of Colombia, Bogota, Columbia.

E-mail: jeman124@gmail.com

\section{Edison Ferney Chala Castillo}

Externado University of Colombia, Bogota, Columbia.

E-mail: edifer3220@ hotmail.com

\section{*) Corresponding Author}

\begin{abstract}
The study aims to innovate the teaching and learning process of mathematics with a group of elementary school students from a rural population of Colombia, where the use of information and communications technology resources, as well as internet access in limited. The teachers implement microlearning so that children learn to solve arithmetic problems. The experience is descriptive with a non-probabilistic convenience sampling, developed from the creation and application of a virtual learning object whose pedagogical strategy was the use of microlearning. The study shows that the use of information and communications technology resources assist the students to learn mathematics. It also develops the office content, skill to interpret, know and solve mathematical problems from everyday situation to students.
\end{abstract}

Keywords: Instrumentalization; instrumentation; arithmetic problems; microlearning.

How to Cite: Mateus-Nieves, E., \& Chala Castillo, E. (2021). Instrumentalization vs Instrumentation of Microlearning in a Math Class. Al-Ta lim Journal, 28(3). doi:https://doi.org/10.15548/jt.v28i3.690

\section{INTRODUCTION}

Martinez et al., 2020 carried out a classroom proposal in 2019, under the Colombian educational model, where the results of external test (SABER tests administered by the Ministry of National Education and applied by the Colombian Institute for the Promotion of Higher Education (ICFES) applied by the state (Rodríguez-Jiménez, 2016), associated with the problem-solving component, in a state public educational establishment, characterized as rural, showed that the school population of fourth and fifth grade of primary school, they have difficulties understanding and solving mathematical problems (Beltrán-Villamizar et al., 2015; Olarte García, 2020). Particularly, because it is difficult for them to identify the data offered by the situation, recognize what it requires, what calculations must be performed to solve it, validate if the response obtained meets the conditions proposed in the problem. Faced with this situation, the group of teachers who teach mathematics, concerned about the low academic results in this subject, applied the proposal in 2019 and in 2020 it was extended to other grades due to the benefits found since $80 \%$ of the classes were remote, given that the students were away due to the confinement decreed by the state, in the presence of the COVID19 pandemic. The results found in the population were outstanding, they allow us teachers to identify elements that are feasible to extend to other levels of basic education and why not to other subjects. 
Learning to solve mathematical problems requires children to carry out relationships as far as possible, create abstract meanings, encode, and decode symbols, elements that make it clear that focusing on a single cause that makes resolution difficult is a mistake (Damayanti \& Mawardi, 2018; Kenedi et al., 2019). For this reason, we seek to specify the learning difficulties in this population. We review how children's mathematical thinking develops, since we assume that learning difficulties arise in this evolutionary process (Abdu et al., 2015; Jonassen, 2010; Kenedi et al., 2019). For this reason, we consider problem solving as a fundamental axis for the teaching and learning processes of arithmetic, understanding operations as one more component of solving them. We analyse the problem situations that students face in their daily lives, as well as the counting strategies they use to solve them (Sahin \& Kirmizigul, 2021; Zhao et al., 2010).

With the development of this work we seek to offer an action proposal for teachers interested in strengthening their educational practices from the implementation of microlearning as a pedagogical strategy since in recent decades technology has become a tool that allows to strengthen these learning considering that By itself it does not create, or store, or disseminate knowledge and therefore it is not used to make any management of it, if factors related to people and the interactions that occur between them are not taken into account (Mateus-Nieves \& Díaz, 2021; Ariza \& Parga, 2011; Mosquera-Suárez et al., 2021). We recognize that the learning of mathematics supposes, together with reading and writing, one of the fundamental learnings of elementary education, given the instrumental nature of these contents.

\section{Instrumental Genesis Theory}

Goos et al. (2009) define the use of mediating instruments in the construction of mental processes with the use of technology by considering two fundamental aspects: Artefact: This refers to all objects of the material culture to which the subject has access during his or her development. Instrument: It is a psychological construct that is generated through the manipulation of the artefact. The point is that the instrument does not exist, a machine or a technical system does not immediately constitute a tool for the subject (Nikitenko \& Mesyats, 2017). Thus, an instrument results from the establishment, by the subject, of an instrumental relationship with the artefact, whether material or not, produced by others or by himself.

Instrumental genesis refers to a progressive construction of the use of an artefact by an actor, for a purpose in a specific environment (Trouche, 2018). While the use of new technologies is proposed to assist in the learning of mathematics (Flecknoe, 2002; Harris, 2002). Haapasalo (2013) proposes an approach in which the genesis of the instrument by the subject is described and highlights the importance of human performance that constructs an instrument through cognitive structures. Hence, instrumental genesis is concerned with two dimensions: instrumentalization and instrumentation. These are configured in the interaction between the subject and an artefact, the latter being understood as anything that can be used and that has been elaborated to be inscribed in intentional activities. In instrumentalization, the evolution, selection and functions of the artefact are studied, giving it characteristics by means of tasks and schemas.

The instrumentalization of the artefact occurs when it is endowed with potentialities and transformed for specific applications (Artigue, 2002). Trouche \& Drijvers (2014) defines it as a process of differentiation of the artefact itself that can go through different stages: discovery, personalisation, and transformation. Instrumentation, on the other hand, analyses the evolution of the schemes of use and their functioning to understand the limitations and potentialities of the instrument. Freiman \& Volkov (2018) defines it as the process where the instrument affects the subject; that is, it allows the subject to develop his activity and to elaborate schemes of instrumented action that allow him to 
construct mathematical knowledge. Artigue (2002) defines it as an action directed towards the subject, each time leading to the development or appropriation of schemes of instrumented action that are oriented towards the understanding of the potential and limitations of the artefact, for optimal development in the solution of a specific task.

A tool is conceived as a mixed entity that comprises both the subject and the artefact, through two components, an artefactual one that is directly identified with the artefact or part of it, and a cognitive one, which corresponds to the techniques and mental schemas that the subject develops and applies while using the artefact (Pérez Medina, 2014). Trouche \& Drijvers (2014) state that the role of the teacher is central in the use of different instruments; this must be planned and coordinated, ensuring that the purpose of their inclusion in the mathematics classroom can be achieved. It requires the teacher to guide the student with pre-planned activities and make changes according to the situation, allowing the student to experience the processes of instrumental genesis.

\section{Adaptive Virtual Learning Environments}

Technological advances have
facilitated access to interpersonal
communication and the dissemination of all
kinds of information; but it has made it
difficult to elucidate the relevant information
for the action that generates knowledge. This
allows us to infer that we are in the era of
knowledge and, at the same time, of
infoxication (Cornella, 2013). We emphasise
that technology should always be considered
a means and not a final objective, hence, the
didactic aspects based on technological tools
are materialised in alternative training
models, such as eLearning with wide
dissemination, for example: MOOCs
(Massive Open Online Courses), which are a
flexible learning modality "participants can
access from anywhere, at any time, and
advance at their own pace".

Mateus-Nieves \& Moreno (2021) indicates that information and communication platforms and technologies must meet the following criteria linked to the SCORM standard: 1) Interoperability, offering the ability to display content regardless of who and how it was created. Produce content independently of the platform on which it will be incorporated. 2) Reusability, focused on reducing production times and increasing content quality. 3) Traceability. Ability to record and track each user and the content they access. 4) Accessibility, the necessary content is always available and can be accessed from anywhere through the available devices. 5) Resilience. Principle aimed at preventing technological obsolescence of content and standards. In other words, adaptability. 6) Scalability. The possibility of systematically growing in terms of content, materials, functionality, and users. In relation to the contents, it states that these must have at least the following characteristics: 1) Quality of the learning objects, 2) Relevance. The appropriateness of the contents and their suitability. 3) User-orientation. Satisfaction of the requirements, expectations and needs of the users. Relating user with (managers, staff, teachers) and external (learners, society in general).

Weller et al. (2005) definition of a virtual learning object (VLO) as: "a digital piece of learning material that addresses a clearly identifiable topic and has the potential to be reused in different contexts". Therefore, we include in the definition the medium of dissemination, i.e., that the learning object can be disseminated through multiple media: computers, tablets, televisions and/or smartphones. Given that, with the massification of mobile technologies, virtual objects have been adapting towards short but concrete fragments that are capable of explaining a concept in its entirety. Arshavskiy (2013) defines it as microlearning. Table 1 shows some advantages of using microlearning. 
Table 1. Advantages of Using Microlearning

\begin{tabular}{|c|c|}
\hline Advantages & Description \\
\hline Facilitates training & $\begin{array}{l}\text { Small information pills or short videos greatly increase the attention and interest of } \\
\text { the students, more so than traditional written methods. } \\
\text { written methods. }\end{array}$ \\
\hline $\begin{array}{l}\text { Increased knowledge } \\
\text { retention }\end{array}$ & $\begin{array}{l}\text { Thanks to the new training techniques and resources applied with microlearning, } \\
\text { the learner remains more attentive and incorporates knowledge more quickly. }\end{array}$ \\
\hline Just on time & $\begin{array}{l}\text { Training can be accessed at any time. In this way, the learning needs of students } \\
\text { can be met, avoiding the time constraints of face-to-face training courses. }\end{array}$ \\
\hline $\begin{array}{l}\text { Accessible on } \\
\text { multiple devices }\end{array}$ & $\begin{array}{l}\text { A plus of microlearning is that it can be designed in such a way that it can be } \\
\text { viewed on multiple mobile devices such as tablets, computers... etc. }\end{array}$ \\
\hline Saving time in training & $\begin{array}{l}\text { Students spend less time in the learning process than in a face-to-face course. The } \\
\text { contents of a microlearning course are short and concise, occupying the learner } \\
\text { only a few minutes a day. This formula is considered a breakthrough for learners } \\
\text { who want to have knowledge quickly and not take a long time to acquire it. }\end{array}$ \\
\hline Motivator & $\begin{array}{l}\text { Microlearning courses are divided into different phases or modules that have to be } \\
\text { passed in order to complete the course. By progressively passing these modules, } \\
\text { the student is self-motivated not to leave the course and to finish it. This gets them } \\
\text { hooked in such a way that they enjoy the process and encourages them to continue } \\
\text { learning, and even encourages them to continue learning, even encouraging them to } \\
\text { take new courses. }\end{array}$ \\
\hline
\end{tabular}

\section{Troubleshooting}

Montero (2015) indicates that a problem is in general terms a task that contains the following components: a) The existence of an interest. That is, when a person or a group of people wants or needs to find a solution. b) The non-existence of an immediate solution: This means that there is no procedure or rule that guarantees the complete solution of the task. For example, the direct application of an algorithm or set of rules is not sufficient to determine the solution. c) The presence of different solution paths or methods (concrete, pictorial, schematic, symbolic, etc.). Here we also consider the possibility that the problem may have more than one solution. d) The attention of the person or group of individuals to perform a set of actions aimed at solving the task. In other words, a problem is a problem until an interest is recognised and specific actions are taken to try to solve it (Zhang \& Lin, 2015).

\section{Types of arithmetic problems}

Urdiain (2006) classifies them into first, second and third level problems. First-level problems, also known as onestep problems, require the application of a single operation for their resolution. He classifies them into additive-subtractive and multiplication-division problems or situations. Second level problems or combined problems, for their resolution it is necessary to perform several operations (two or more) in a certain order. They are more complex than those of the first level as they involve establishing more complex relationships between the data provided by the statement. Third level problems are those in which the data in the statement are given in the form of decimal, fractional or percentage numbers. In this paper we only consider first and second level arithmetic problems given the level of schooling attained by the children.

\section{METHOD}

The experience is approached from the qualitative approach, using action research as "a form of enquiry carried out by teachers to improve their teaching actions and which makes it possible to review their practice in the light of evidence obtained"(Andrés \& Berrueco, 2011; Bulla, 2011). The population of this research belongs to a rural municipality in the department of Cundinamarca in Colombia. The experience was initially focused on the sample, 15 students, 5 of 
whom are in 4th grade and 10 in 5th grade of primary school at the central headquarters (February and March 2020). After 27 March, when the national government decreed a pandemic lockdown, we were obliged to extend the sample to the population.

The experience was carried out in three stages: 1) Exploration and analysis of infrastructure: we determined the possibilities and limitations of implementing a digital school environment in the institution. We characterised the sample in terms of digital competences and defined the necessary human and technological resources compared to the infrastructure offered by the school. 2) Intervention: we designed and implemented educational software on the Flash platform in Action Scrip 2.0 programming language. 3) We evaluated the experience.

The first moment of exploration, we designed two instruments: A practical workshop that sought to determine whether the students had any training in digital competences or digital literacy. Digital competence is understood to mean that the student knows and manages hardware and software. And digital literacy is the process of developing basic skills for the use of ICT, particularly in relation to the use of a computer and Internet browsing (Ministry of Information and Communication Technologies, 2015). And a diagnostic test with mathematical problems related to their rural context, in order to determine the level of competences that the children possess when using their mathematical knowledge in problem situations. Both the workshop and the diagnostic test were applied in written form to the population (two groups of fourth and fifth grades of primary school, equivalent to 50 students, whose ages range from 8 to 12 years old).

The second stage of the intervention was divided into three stages. Based on the results of the first stage, we designed an VLO with educational software (on the Flash platform in Action Scrip 2.0 programming language), based on the solution of arithmetic problems, using microlearning as a strategy. The educational software has micro-activities for students to solve mathematical problems related to the rural context in which they live. We guide children to apply basic arithmetic operations in various scenarios known to them, aided by multimedia elements such as images, graphics, sounds, micro videos, micro activities and video tutorials, seeking to be a support in improving the mathematical skills of children.

In the second stage, we carried out a literacy training for the sample that allowed us to improve the children's digital skills, use of the computer and some applications of educational software. Marqués (2015) refers to educational software as computer programs created for the specific purpose of being used as a didactic medium, i.e., to facilitate teaching and learning processes. In the third stage, we designed and applied a didactic sequence of activities (VLO) with educational software) that involved the use of level 1 and 2 mathematical problems. This stage was initially developed using paper and pencil, appealing to the strategies and heuristics of each student, with the support of the research team. We then developed it using the educational software designed, so that the students discovered its usefulness and the benefits it offers. We allowed them to manipulate it, to get to know it until it became a learning tool throughout the work sessions. Here the artefact was already an instrument for the students because it helped them to confront and solve everyday problem situations in their environment. We wanted the students to identify instrumentalization as the process of going through different stages: discovery, personalisation and transformation of the artefact into a tool. 
The third stage was the collection of information. We systematised the data from the population characterisation surveys (entry, diagnostic test and processoutput evaluation test), field diaries, operation sheets where the students developed their exercises and the answers saved in the software. The results of the intervention were analysed by means of matrices that made it possible to triangulate the information and show the results of the research process. It is important to note that to organise the information it was necessary to quantify through indicators the level of use or application of the elements contained in the checklists, both in terms of the steps to solve the problems and the activities aimed at checking whether the software could be considered a learning tool.

For the entry and exit tests, we used the same questions. For the input test, we first did it with paper and pencil, given that the population is rural and during the month of April there were no cases of COVID19 in the municipality, which allowed us to summon the children to the institution to apply it. This allowed us to summon the children to the institution to apply it, while the exit survey was carried out remotely, directly in the software. This helped to organise the information by categories, allowing us to reflect on how the students progressed during each of the situations presented, so that when errors or difficulties were encountered, feedback was provided in order to solve them. Regarding the evaluation of the impact of the educational software: we measured the instrumentation, analysing with the children the evolution of the use and functioning schemes, seeking to understand the limitations and potential of the instrument (educational software). At this point, we assessed the impact of the software in terms of the development of mathematical competencies achieved by the students, linked to the solution of mathematical problems and the handling and use of the educational tool.

\section{RESULTS AND DISCUSSIONS}

The first stage of exploration allowed us to characterise the population, which belongs to farming families whose occupation is the household, agriculture, and trade in the products they grow. As for the level of academic education, only $46 \%$ managed to finish primary school; of these, $30 \%$ completed secondary school. The children have studied their entire primary education in this school. In addition, we found that $80 \%$ of the population reported having access to a smartphone at home, either because it belongs to their parents or a close relative. Of that $80 \%$, only $35 \%$ have a data plan that allows them to access the internet at any time. This led us to select a sample of students who could access the internet from a device, computer, tablet, smartphone (15 in total), with the aim that, at some point during the day, they could contact those children who did not have it and share "class time", develop the proposed activities while they are not at school, because when they are in the rural institution, they have access to the internet from computers provided by the municipality. Our interest was that everyone should have internet connectivity 24 hours a day, 7 days a week.

Of the 15 students, 6 are twelve years old, are in grade 5 and have repeated a school grade with poor academic performance as a cause. Although the population reported having access to smartphones, digital illiteracy was perceived in all of the children, due to economic difficulties that do not allow them to have access to computers, laptops or tablets at home. The only access they reported having to these devices was during their time at school. The young age of the children means that they are not interested in the massive use of these resources; however, they show interest in them, but not as a necessary and fundamental tool for their learning process. Smartphone use is limited to calls and the 
use of two social networks (WhatsApp and Facebook).

We conducted training on the use and management of hardware and software, seeking to develop digital skills. We showed them the usefulness of smartphones as a mobile device "artefact" that can become a tool for solving specific problems in their environment. Figure 1 shows the VLO interface that they had to download to their devices via the internet.

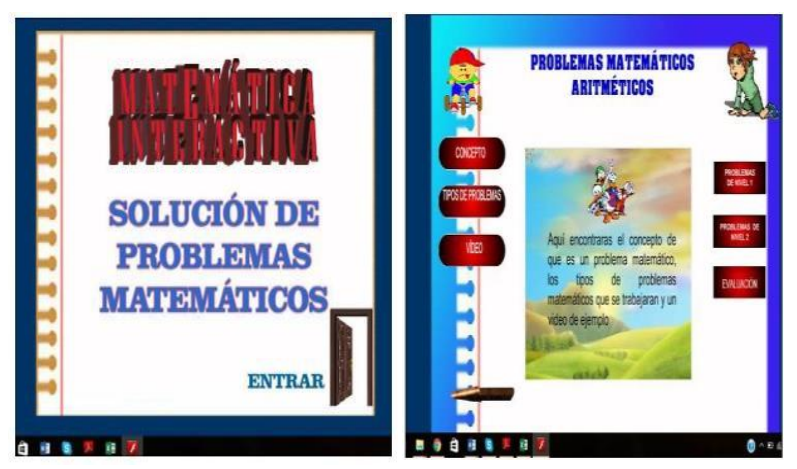

Figure 1. Interface of the educational software (VLO). Source: Own creation

On the right side of Figure 1 we can see six components in which the software incorporates micro modules (concepts, problem types, videos, solved problems of level 1, 2 respectively, and an evaluation). Each of these components has specific micro problem situations of arithmetic type; each module has a type of problem and within each type of problem there are different specific didactic situations with contextual problems to the students' environment. We emphasise that in each problem situation there is a help icon that allows the student to explore or demonstrate different strategies for its solution. At the request of the students, we included the multiplication tables as an extra element of help, given that for their age and grade level, there are still failures in the learning and use of these tables; in the same way, we inserted an algorithm as a "simple calculator" that helps them to carry out and validate mathematical calculations quickly, using the four basic operations.
Microlearning was implemented for the type of exercises proposed and the way we taught them to identify what type of problem (1 or 2$)$ they were presented with. We emphasised that the child should identify the data the problem provides, the question to be solved and the operation to be applied. We built in the VPA a bank of problems that are randomly displayed when the student clicks on the icon "level 1 problems" located at the top right of the screen. Figure 2 shows the interface of one of these problems.

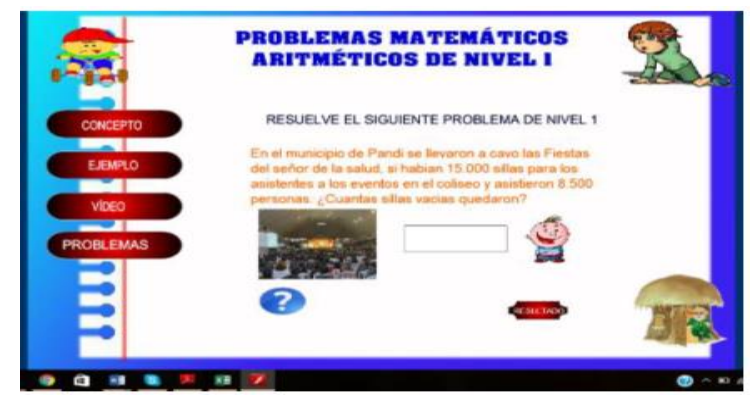

Figure 2. Interface of the level 1 problem bank Source: Own creation

In Figure 2 we observe four components on the left side of the screen (concept, example, video, problems) that allow the student to navigate through the VLO in such a way that if he has forgotten a concept explained in the initial part, he can review it, if he wishes to review the example step by step, he can do so; watch the micro video where he is offered general heuristic strategies useful for solving this type of problem by clicking on the help button located at the bottom with a question mark, or if he has already solved the proposed problem go to the problem bank to solve others. There are also two components aligned horizontally at the bottom of the screen (a blue button that changes to red when the mouse pointer passes over it, which allows you to validate whether the answer typed by him is correct, or if not, you have the option to use the algorithm that serves as a "calculator". The other button with the image of a leprechaun's house (when clicked, students return to the main screen 
of the software); elements that allow the student to clarify doubts and in case the answer typed is incorrect, return to the proposed problem situation, to review the components and/or help calculations vertically aligned on the left side of the screen.

Figure 3 shows the VLO interface with an example similar to the previous one, but with level 2 problems. In this type of problem, it was necessary to involve a step-by-step explanation of how to perform this type of problem, identifying when and how to apply one operation before the other, for example when addition and multiplication are involved. These aids were placed in the level two problems because during the process it became evident that the students had procedural difficulties in: subtraction by lending, application of the distributive property and in the correct application of the multiplication algorithm.

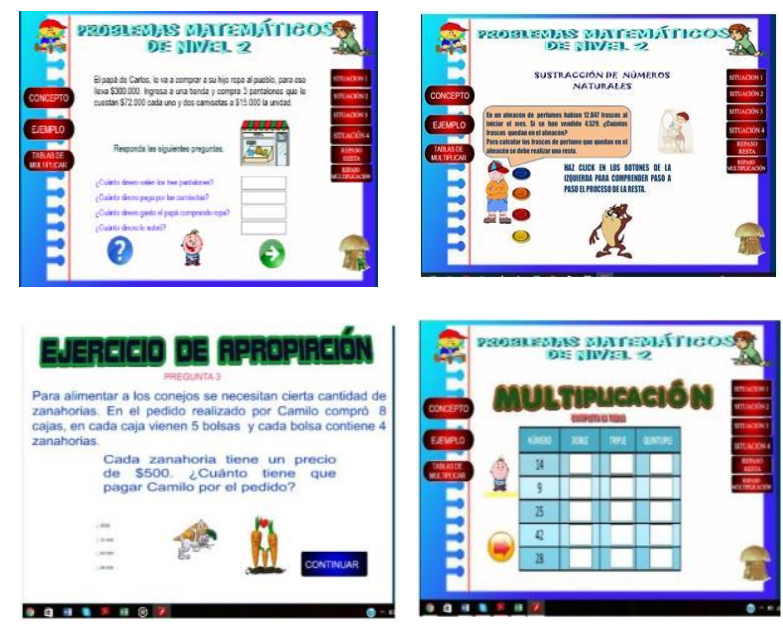

Figure 3. Images of the software's graphical interface (level 2 problem bank). Source: Own creation

Within the design of the software, the students have the facility to enter a help module where, through a micro video tutorial, it is explained to them what elements must be considered to solve the proposed problem situation, as well as what operations they can perform depending on the vocabulary or key words within the problem. As we progressed in the use of the software, we could observe that the students were already using this tool very little, which allowed us to infer that they recognise and apply several similar strategies or heuristics to reach a correct answer to the solution.

For the question bank, we considered problems of the type of changejoin and change-separate, "involving addition or subtraction respectively". Combination problems where they had to consider the integration of quantities to find totals "such as number of hens and roosters in a pen". Comparison-type problems where they had to indicate which represented more quantity, which was taller than, which is bigger than "e.g., situations where they were asked to measure the height of a carrot plant compared to the height of a corn plant". Matching problems by adding "e.g., on their parents' farm there are 3 bulls, the number of cows is twice the number of bulls plus 2, how many bulls should be brought to the farm so that there are the same number of bulls and cows? Equalising problems by removing "e.g.: in a farmyard there are 14 laying hens, Maria the owner of the farmyard lends her neighbour Helena two hens for 4 days. We know that each hen lays one egg every day, how many eggs has Maria collected at the end of the 4 days? Among others.

\section{Integration between the theory of instrumental genesis and Adaptive Virtual Learning Environments (AVL)}

We highlight the gradual development of office contents, as well as the use of tools: recognition of help elements, navigability buttons from one scene to another, complementary activities, screen capturing, file attachments, use of digital boards, improvement in reading comprehension, skills to find strategies to solve the proposed problems. We highlight the qualification that the students achieved in the creation of content, which allows us to infer that microlearning can be used as an application in which the teacher 
determines which learning units to deliver, when, where, and in which the student decides when and how to access the learning resources. Figure 4 shows some of the children in the sample working on the platform during short stays at the school.
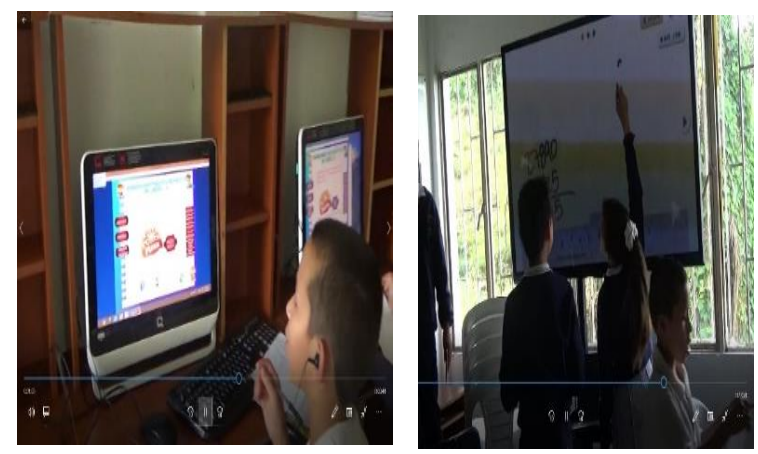

Figure 4. Picture of some children working on the platform.

We can see that the students went from using the educational software as a learning tool (instrumentalization) through the recognition of the graphic interface, the identification of icons and instructions, to using the software as a learning tool (instrumentation) through interaction with it, investigating its utilities that would allow them to improve their mathematical reasoning and heuristics by navigating through each of the didactic situations presented there. This indicates that in the course of the activities proposed, the children managed to internalise the software tools and use them for a purpose other than their simple use, for example, student E3 mentioned: "I taught my dad to use the programme's calculator on Sunday when we went down to the market in town" in this case they used the software from their Smartphone as a tool to solve everyday problems in their work.

Frequent use of the educational software "instrumentation" allowed the children, who at the beginning of the process showed apathy towards learning mathematics, to show a different attitude at the end of the process. The learning and understanding of office automation tools enabled them to develop competences for interpreting, representing, formulating, and executing problem situations, but the competence to reason and argue was weak. In this aspect, we noticed that the young age of most of the students in the sample did not allow them to express, and in some cases to understand, a technical vocabulary appropriate to the level of the problems they were presented with. Here it was necessary to remind them of the importance of using the dictionary to find out the meaning of terms such as "double, the third, triple, among others". In figure 5 we share the production of student E14 where he formulates a problem situation, but his reasoning and argumentation are weak, a subject to be dealt with in another paper:

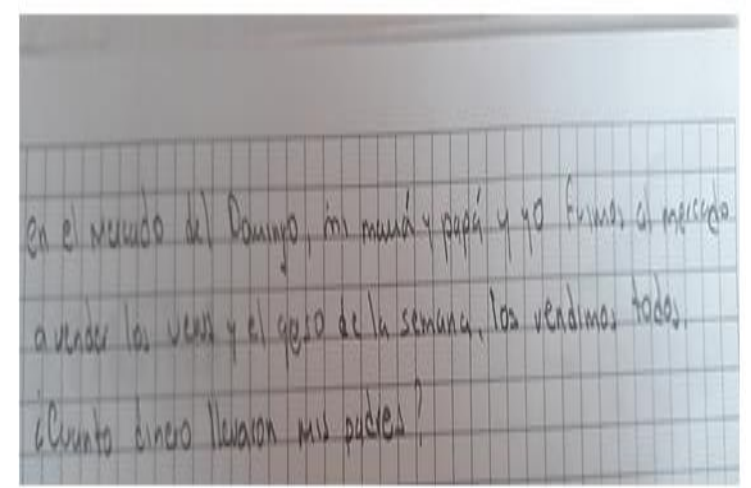

Figure 5. Production of student E14.

At the end of the intervention, we noticed that in terms of Trouche (2004) instrumentalization as a process of differentiation of the artefact itself allowed the children to discover, personalise and transform their environment, to the point that the population (children and parents) requested that the training in the use of the interactive software be extended to all the students, given that they observed in the children with whom they developed this work, The development of skills and competencies in the use of electronic devices to learn mathematics motivated these researchers to extend this experience for the next year, with the prior consent of the institution's administration, despite the connectivity difficulties that most of them have while they are not at school: 
evolution of the schemes of use and operation to understand the limitations and potential of the instrument". The development of this work evidenced pleasure and interest in the use of the software as a useful tool that invites them to think and reason mathematically.

\section{In relation to problem solving}

Using the mathematical problemsolving strategy proposed by Lee (2016) to teach mathematics or to reinforce concepts made it possible to identify that the problem statements were related to the children's immediate context. It showed the importance of mathematics in its double vision: as a science and as a useful tool in everyday life. The teaching of mathematics through problem solving under the microlearning strategy allowed for greater possibilities of appropriation of both concepts and processes that bring this science closer to the immediate reality of the student, "problems are used as vehicles at the service of other curricular objectives" (Blanco Nieto et al., 2015; Pérez \& Ramírez, 2011), Therefore, we consider it important that primary school teachers not only focus their work on the presentation of mathematical algorithms, sometimes without a real context for the student, but that they can give them real meaning from the approach of situations specific to the school environment where they work, seeking to integrate ICTs as useful tools in the process. We found that the use of software, from the microlearning approach, helps in the formation of strategies or heuristics in the solution of arithmetic mathematical problems, allowing the student to develop interpretative and procedural skills to address a variety of arithmetic problems related to the student's immediate context, complementing previous knowledge, and achieving a horizontal mathematics, i.e., translating from the real world to the mathematical world.

\section{Difficulties encountered in this classroom experience}

The fact that they belong to a rural population offers many difficulties for the educational community, given that their parents must move from one municipality to another to harvest crops, a fact that motivates the students to move from one institution to another, thus generating the progressive development of the advanced processes. Other children are left in the midst of a conceptual chaos that motivates them to drop out of school because they feel that they are lagging behind in the processes and are not keeping pace with their classmates. Here, we saw another problem: the extra age for the primary grades. We saw 9-year-olds sharing classrooms with 11- or 12-year-olds, a situation that demotivates older children in comparison with their peers.

We found that most of the support for academic homework is provided by the mother and siblings; $21 \%$ of the sample had no one at home to help them with homework or schoolwork. As an additional element, we found that more than half of the population does not have computers, tablets, or smartphones at home to do homework or for entertainment activities; they only have access to them at school or in an internet café. What we found to be positive is that at least in the sample, one person in the family has a Smartphone with internet access according to a contracted data plan, which motivated us, according to the requests made by the parents themselves, to invite them to a workshop for parents, tell them about the project developed, we sought to integrate their children in the management and use of educational software, we guided them to download the software and allow the children to develop the experience from their Smartphone. We found that at the end, not only the students had access and use of the software, but their parents and siblings also made use of it because they 
considered it a novel and useful tool for their daily lives.

\section{CONCLUSION AND RECOMMENDATION}

We present conclusions in two directions: the first integrating the theory of instrumental genesis with Adaptive Virtual Learning Environments. The second is related to problem solving with an emphasis on the development of competences in children. First, among the many current platforms for creating MOOCs, we chose Flash Action Scrip 2.0 because it allows the integration of multimedia elements that make the user interface user-friendly, especially for children, without neglecting the SCORM standards. This process of developing the software from contextual knowledge makes it easier to use, as it has a clear intention towards the user. It also allows the teacher to make modifications according to the subject matter and level of difficulty required. It is important to emphasise that care must be taken in its design, as its navigability must be intuitive, it must generate interest and not lead to confusion in its use. Care should be taken not to saturate the software scenes with images or content, so that the child can gradually approach the software and turn it into a learning tool. Moving from the artefact to the tool. From the instrumentalization of the artefact to the instrumentation of the artefact.

Second, among the obstacles identified is dyscalculia, a learning difficulty that affects the understanding of mathematical calculations, making it difficult for them to interpret the situations presented. We were able to identify verbal dyscalculia, understood as difficulty in naming numbers and quantities, use of terms and the relationships between them, particularly when they are related to multiplication or division. In some children we identified graphic and lexical dyscalculia, understood as difficulty in writing and reading mathematical symbols, including $\neq, \div, \notin$. In some children we found evidence of operational dyscalculia, given that they alter the execution of operations and numerical calculations. Aspects to be considered in another classroom experience.

We note that the structuring of the mathematical experience must be considered as a fundamental element given that pupils support some knowledge over others, so that, if there are still competencies to be assimilated, subsequent learning will be extra difficult. We recommend that primary school teachers recognise that difficulties in problem solving are the classic obstacle to learning mathematics. We show that this impediment is directly related to reading comprehension, since the interpretation of the problem requires a series of linguistic skills to assimilate concepts and processes such as the application of rules or translation from one language to another. An aspect to be considered by teachers in the planning of their academic activities, who propose that the work of teachers should be mediated by a strong, organized, structured and concrete disciplinary component in which the Didactic Content Knowledge, plays a fundamental role, which aims to integrate a clear and solid mathematical theoretical component with a digital tool that supports student learning.

\section{REFERENCES}

Abdu, R., Schwarz, B., \& Mavrikis, M. (2015). Whole-class scaffolding for learning to solve mathematics problems together in a computersupported environment. ZDM, 47(7), 1163-1178. https://doi.org/10.1007/s11858015-0719-y

Andrés, M. M., \& Berrueco, R. F. (2011). Investigación práctica en educación: Investigación-acción. 
Actas de Las XVII JENUI, 359365.

Ariza, L. G., \& Parga, D. L. (2011). Content knowledge didactic curriculum for teaching the combustion. Educación Química, $22(1), 45-50$.

Arshavskiy, M. (2013). Instructional Design for ELearning: Essential guide to creating successful eLearning courses. CreateSpace Independent Publishing Platform.

Artigue, M. (2002). Learning mathematics in a CAS environment: The genesis of a reflection about instrumentation and the dialectics between technical and conceptual work. International Journal of Computers for Mathematical Learning, 7(3), 245-274. https://doi.org/10.1023/A:1022103 $\underline{903080}$

Beltrán-Villamizar, Y. I., MartínezFuentes, Y. L., \& Vargas-Beltrán, Á. S. (2015). The Colombian Educational System on the Road to Inclusion: Progress and Challenges. Educación y Educadores, 18(1), 62-75.

Blanco Nieto, L. J., Cárdenas Lizarazo, J. A., Caballero Carrasco, A., Cáceres García, M. J., Carvalho, J. L. T., Casas García, L. M., Contreras González, L. C., Chamoso Sánchez, J. M., Figueiredo, C. A. B. P. A. de, \& Gómez del Amo, R. (2015). La resolución de problemas de Matemáticas en la formación inicial de profesores de Primaria. Cáceres: Universidad de Extremadura, Servicio de Publicaciones, 2015.

Bulla, C. M. F. (2011). La investigaciónacción: Conocer y cambiar la práctica educativa.
Revista Docencia Universitaria, 12(1), 132-135.

Cornella, A. (2013). Ideas valor resultados. Books Infonomía.

Damayanti, R., \& Mawardi, M. (2018). Developing of MITRA learning model of problem solving-based to solve mathematical problems in elementary school. Jurnal Prima Edukasia, 6(1), 1-10. DOI: http://dx.doi.org/10.21831/jpe.v6i1. $\underline{17238}$

Echenique Urdiain, I. (2006). Matemáticas: Resolución de problemas.

Flecknoe, M. (2002). Measuring the Impact of Teacher Professional Development: Can it be done? European Journal of Teacher Education, 25(2-3), 119-134.

Freiman, V., \& Volkov, A. (2018). History of Computations, Computing Devices, and Mathematics Education from the Teaching and Learning Perspective: Looking for New Paths of Investigation. In Computations and Computing Devices in Mathematics Education Before the Advent of Electronic Calculators (pp. 3-21). Springer. DOI: $\quad \underline{10.1007 / 978-3-319-73396-}$ $\underline{8} 1$

Goos, M., Soury-Lavergne, S., Assude, T., Brown, J., Kong, C. M., Glover, D., Grugeon, B., Laborde, C., Lavicza, Z., \& Miller, D. (2009). Teachers and teaching: Theoretical perspectives and issues concerning classroom implementation. In Mathematics education and technology-rethinking the terrain (pp. 311-328). Springer. DOI: 10.1007/978-1-4419-0146-0_14

Haapasalo, L. (2013). Adapting assessment to instrumental genesis. The 
International Journal for Technology in Mathematics Education, 20(3), 87.

Harris, S. (2002). Innovative pedagogical practices using ICT in schools in England. Journal of Computer Assisted Learning, 18(4), 449-458. https://doi.org/10.1046/j.02664909.2002.00256.x

Jonassen, D. H. (2010). Learning to solve problems: A handbook for designing problem-solving learning environments. Routledge.

Kenedi, A. K., Helsa, Y., Ariani, Y., Zainil, M., \& Hendri, S. (2019). Mathematical Connection of Elementary School Students to Solve Mathematical Problems. Journal on Mathematics Education, 10(1), 69-80.

Lee, C. I. (2016). An appropriate prompts system based on the Polya method for mathematical problem-solving. Eurasia Journal of Mathematics, Science and Technology Education, 13(3), 893-910. https://doi.org/10.12973/eurasia.20 $\underline{17.00649 \mathrm{a}}$

Martinez, I., Garcia, F., Veiga, F., Garcia, O. F., Rodrigues, Y., \& Serra, E. (2020). Parenting styles, internalization of values and selfesteem: A cross-cultural study in Spain, Portugal and Brazil. International Journal of Environmental Research and Public Health, 17(7), 2370. https://doi.org/10.3390/ijerph17072 $\underline{370}$

Mateus-Nieves, E., \& Díaz, H. R. D. (2021). Development of Mathematical Thinking Skill from the Formulation and Resolution of Verbal Arithmetic Problems. Acta Scientiae, 23(1), 30-52.

\section{DOI:10.17648/ACTA.SCIENTIAE} .5845

Montero, Y. H. (2015). Experiencia de usuario: Principios y métodos. Experiencia de Usuario: Principios y Métodos, 9.

Mosquera-Suárez, C. J., Alonso, M. X., Marín-Velasco, A. S., PradaMurcia, L. E., Rincón-Núñez, J. P., \& Saldaña-Lozano, L. S. (2021). Didactic content knowledge, impact on the practical knowledge of science teachers and on the scholar scientific knowledge. Revista Científica, 40, 45-62.

Nikitenko, S. M., \& Mesyats, M. A. (2017). Objects of industrial property as an instrument for introducing technological innovations in machine building. IOP Conference Series: Materials Science and Engineering, 253(1), 012024.

Olarte García, J. A. (2020). Standardizing the Use of Mathematical Models: A Challenge Faced by the Colombian Educational System. Revista Educación, 44(1), 230-244.

Pérez Medina, C. R. (2014). Enfoques teóricos en investigación para la integración de la tecnología digital en la educación matemática. DOI: 10.4151/07189729-Vol.53-Iss.2$\underline{\text { Art. } 200}$

Pérez, Y., \& Ramírez, R. (2011). Estrategias de enseñanza de la resolución de problemas matemáticos: Fundamentos teóricos y metodológicos. Revista de Investigación, 35(73), 169-194.

Rodríguez-Jiménez, O. R. (2016). The consistency and stability of school effect in Colombian high school education. The European Journal of Multidisciplinary Sciences. 
DOI: $10.15405 /$ ejms $(2421-$ $\underline{8251) .2016 .1 .2}$

Sahin, Z. G., \& Kirmizigul, H. G. (2021). The Effect of Mathematics Teaching Through Micro Learning in the E-Learning Environment on Conceptual and Procedural Knowledge. Virtually Hosted, Florida, USA, 159. DOI: https://www.doi.org/10.5038/25726374-v4

Trouche, L. (2018). Instrumentalization in mathematics education. Springer. DOI: 10.1007/978-3-319-774879_100013-1

Trouche, L., \& Drijvers, P. (2014). Webbing and orchestration. Two interrelated views on digital tools in mathematics education. Teaching Mathematics and Its Applications: International Journal of the IMA, 33(3),

193-209.

DOI: $10.1093 /$ teamat/hru014
Weller, M., Pegler, C., \& Mason, R. (2005). Use of innovative technologies on an e-learning course. The Internet and Higher Education, 8(1), 61-71. https://doi.org/10.1016/j.iheduc.200 $\underline{4.10 .001}$

Zhang, X., \& Lin, D. (2015). Pathways to arithmetic: The role of visualspatial and language skills in written arithmetic, arithmetic word problems, and nonsymbolic arithmetic. Contemporary Educational Psychology, 41, 188197.

https://doi.org/10.1016/j.cedpsych. $\underline{2015.01 .005}$

Zhao, X., Wan, X., \& Okamoto, T. (2010). Adaptive content delivery in ubiquitous learning environment. 2010 6th IEEE International Conference on Wireless, Mobile, and Ubiquitous Technologies in Education, 19-26. DOI: $10.1109 /$ WMUTE.2010.10 